\title{
Standar Penerapan Wisata Halal Bagi Pelaku Industri Parawisata Di Kota Bandung
}

\author{
Merita Bernik ${ }^{1,}$ Deru R Indika ${ }^{2,}$ Rita Komala Dewi ${ }^{3}$. \\ ${ }^{1}$ Universitas Padjadjaran \\ ${ }^{2}$ Universitas Padjadjaran \\ ${ }^{3}$ Universitas Padjadjaran
}

\section{ARTICLE INFO}

Article history:

Received: May 2019

Accepted: June 2019

Published: $1^{\text {st }}$ Juli 2019
Keywords:

Halal Tourism, Halal Standardization, Culinary, SMEs.

\section{ABSTRACT}

Bandung is one of the halal tourist destinations in Indonesia. With the increasingly rapid growth of cafes and restaurants, the competition is getting tougher. One of the highlights is whether the café and restaurant are halal certified. This becomes very important because Indonesia is one of the largest Islamic countries in the World. It is proper if halal is the main concern. The business people do not understand and realize the importance of fulfilling the halal standard set by the government. So through this community service will be carried out socialization regarding required halal tourism. The method used in this study is the Deplat Pastisipatif which is conducting activities in the form of providing counseling and guidance on halal tourism and halal standardization on SMEs in the culinary sector in the city of Bandung, especially the Jatinangor region. Counseling was carried out by inviting from the tourism, youth and sport agency and also the MUI. Culinary business begin to understand halal standardization and the importance of having halal certification. There is still a need for assistance to be able to implement halal tourism properly.

How to cite: bernik, merita. (2019). Standard of Implementation Halal Tourism for Tourism Industry in Bandung City. Jurnal Pemberdayaan Masyarakat Madani (JPMM), 3(1), 83 - 93. https://doi.org/10.21009/JPMM.003.1.6

* Corresponding Author.

Deru@unpad.ac.id (Deru R Indika) 


\section{PENDAHULUAN}

Indonesia merupakan salah satu negara dengan penduduk muslim terbesar di dunia, dengan jumlah sekitar 209,1 juta jiwa menurut Pew Research, sebuah lembaga riset global (2016). Oleh karena itu, potensi pariwisata halal menjadi suatu hal yang sangat potensial mengingat pasar pariwisata halal juga telah menjadi tren global. Menurut Timothy \& Olsen (2006) dengan adanya potensi pariwisata halal yang besar, maka hal tersebut berimplikasi pada peningkatan wisatawan dengan motivasi agama. Kondisi tersebut telah menarik perhatian akademisi, pemerintah, dan lembaga pariwisata untuk mengembangkan pariwisata.

Kota Bandung merupakan salah satu destinasi wisata halal di Indonesia. Wisata halal meliputi hotel halal, resort halal, restoran halal dan perjalanan halal. Dengan semakin maraknya pertumbuhan kuliner di kota Bandung, maka mengenai kuliner yang disajikan baik di café, restoran ataupun rumah makan tentu saja merupakan kuliner yang seharusnya terjamin kehalalannya. Akan tetapi kehalalan tersebut bukan hanya pernyataan tetapi harus dibuktikan secara nyata bahwa kuliner tersebut memang bersertifikasi halal. Pemahaman mengenai halal ini masih kurang tersosialisasi dengan baik di masyarakat. banyak pengelola café, restoran atau rumah makan belum mengetahui apa yang sebaiknya dilakukan untuk dapat menjamin bahwa kuliner yang disajikan memang benar-benar halal. Salah satu yang dipersyaratkan dalam wisata halal bahwa café, restoran ataupun rumah makan harus mencantumkan label halal. Farida Ningsih (2016) menyatakan bahwa Masyarakat Indonesia yang mayoritas muslim merasa tidak perlu mencantumkan label halal di restoran, hal ini berbeda dengan di luar negeri yang sudah banyak restoran yang mencantumkan label halal. Upaya yang dapat dilakukan untuk mensoasilisasikan mengenai wisata halal salah satunya melalui program pengabdian pada masyarakat.. Program pengabdian pada masyarakat ini dilaksanakan di Jatinangor yang merupakan salah satu bagian dari kota Bandung. Jatinangor merupakan daerah yang mulai berkembang dengan pesat seiring tumbuh dan berkembangnya perguruan tinggi di sana. Banyaknya mahasiswa menyebabkan semakin meningkatnya kebutuhan akan makanan, sehingga di jatinangor tersebut banyak sekali UKM yang bergerak di bidang kuliner seperti restoran, café dan rumah-rumah makan.

Kegiatan yang akan dilaksanakan dalam program pengabdian pada masyarakat ini adalah mensosialisasi mengenai wisata halal untuk para UKM yang bergerak dibidang kuliner, bekerjasama dengan kecamatan Jatinangor, MUI dan juga Dinas Pariwisata, Kebudayaan, Pemuda dan Olah Raga. Tujuan dari program pengabdian kepada masayarakat ini adalah para UKM yang bergerak dibidang kuliner memahami mengenai wisata halal, kemudian menyadari pentingnya memenuhi standarisasi halal dari kuliner yang dihasilkannya. Manfaat yang yang akan diperoleh dari kegiatan ini adalah semakin banyaknya UKM yang memahami mengenai 
wisata halal dan mengetahui prosedur yang harus dilakukan agar kuliner yang dihasilkannya dapat tersertifikasi halal.

\section{KAJIAN TEORITIK}

Pada saat ini konsep halal telah menjadi gaya hidup masyarakat di dunia maupun masayarakat Indonesia, karena konsep halal dewasa ini tidak hanya di gunakan pada makanan dan minuman namun juga telah digunakan dalam aspek lain seperti fashion, kosmetik, sistem keuangan serta pariwisata. Menurut Zulkifli (dalam Akyol \& Kilinç 2014, 171-186), pasar halal diklasifikasikan kedalam tiga kategori yaitu: makanan, gaya hidup (kosmetik dan tekstil), dan pelayanan (paket wisata, keuangan, transportasi).

Wisata halal adalah pariwisata yang melayani liburan, dengan menyesuaikan gaya liburan sesuai dengan kebutuhan dan permintaan traveler muslim”. Dalam hal ini hotel yang mengusung prinsip syariah tidak melayani minuman beralkohol dan memiliki kolam renang dan fasilitas spa terpisah untuk pria dan wanita. Dalam wisata halal, destinasi yang menjadi tujuan harus meyediakan makanan yang halal, mudah untuk akses ke tempat ibadah dan memberikan pelayanan yang sesuai dengan standar syari'ah (Jaelani, 2017). Tersedianya makanan yang halal, produk yang tidak mengandung babi, minuman yang tidak memabukan, ketersediaannya fasilitas ruang ibadah termasuk temoad wudhu, tersedianya Al Quran dan tempat ibadah di kamar, petunjuk kiblat dan pakaian staf yang sopan merupakan syarat yang menciptakan suasana yang ramah untuk muslim
(Satriana, Faridah, 2018).

Undang-undang jaminan produk halal no 33 tahun 2014, Pasal 4 menyatakan bahwa produk yang, beredar, dan diperdagangkan di wilayah Indonesia wajib bersertifikasi halal. Ayat 67 menyatakan kewajiban bersertifikat halal bagi produk yang beredar dan diperdagangkan di wilayah Indonesia sebagaimana dimaksud dalam pasal 4 mulai berlaku 5 tahun sejak UU ini diundangundangkan.

Untuk lebih memahami perbedaan antara wisata konvensional, wisata religi dan wisata syariah atau halal dapat dijelaskan dalam Tabel 1.

\section{MATERI DAN METODE}

Dalam kegiatan ini metode pelaksanaan yang dipergunakan adalah metode Deplat Partisipatif yaitu melakukan kegiatan dalam bentuk pemberian penyuluhan dan bimbingan mengenai wisata halal dan standarisasi halal pada UKM dalam sektor kuliner di kota Bandung khususnya wilayah Jatinangor.

Sosialisasi diberikan kepada café, restoran atau tempat makan disekitar jatinangor yang berjumlah 30. Untuk pendampingan dilakukan terhadap cefe, restoran dan rumah makan yang belum memiliki sertifikasi halal dan bersedia mengikuti prosedur untuk memperoleh sertifikasi halal.

Kegiatan penyuluhan dan bimbingan ini dilaksanakan dalam bentuk memberikan informasi dan juga sosialisasi mengenai wisata halal dan standar halal yang sebaiknya dipenuhi oleh UKM kuliner tersebut. Tahapan 
Kegiatan Pengabdian Kepada Masyarakat yang akan dilaksanakan terdapat pada tabel 2. Berdasarkan 7 tahapan kegiatan yang akan dilakukan mulai dari mengidentifikasi UKM di Jatinangor hingga melaksanakan FGD, maka pengukuran keberhasilan dari sosialisasi wisata halal yang berupa perbandingan sebelum dan setelah dilaksanakannya kegiatan ini terdapat pada tabel 3. Berdasarkan tabel 3 menunjukkan bahwa hasil yang diinginkan adalah adanya perubahan yang berarti sebelum dan setelah dilakukannya sosialiasi mengenai wisata halal, masyarakat diharapkan menjadi tahu, paham dan dapat memenuhi standar halal.

\section{HASIL DAN PEMBAHASAN}

Pemahaman wisata halal dapat ditinjau dari beberapa aspek seperti aspek sosial dan politik, ekonomi dan mata pencarian, komunikasi, dan budaya masyarakat. Adapun pemahaman tersebut berdasarkan hasil wawancara dan observasi di lapangan adalah sebagai berikut:

\section{Asfek Sosial dan Politik}

Pariwisata bisa menjadi sebuah tujuan dari pelaksanaan diplomasi publik dalam rangka meningkatkan hubungan antar negara. Pariwisata adalah industri besar dan berpengaruh terhadap publik. Pariwisata merupa-

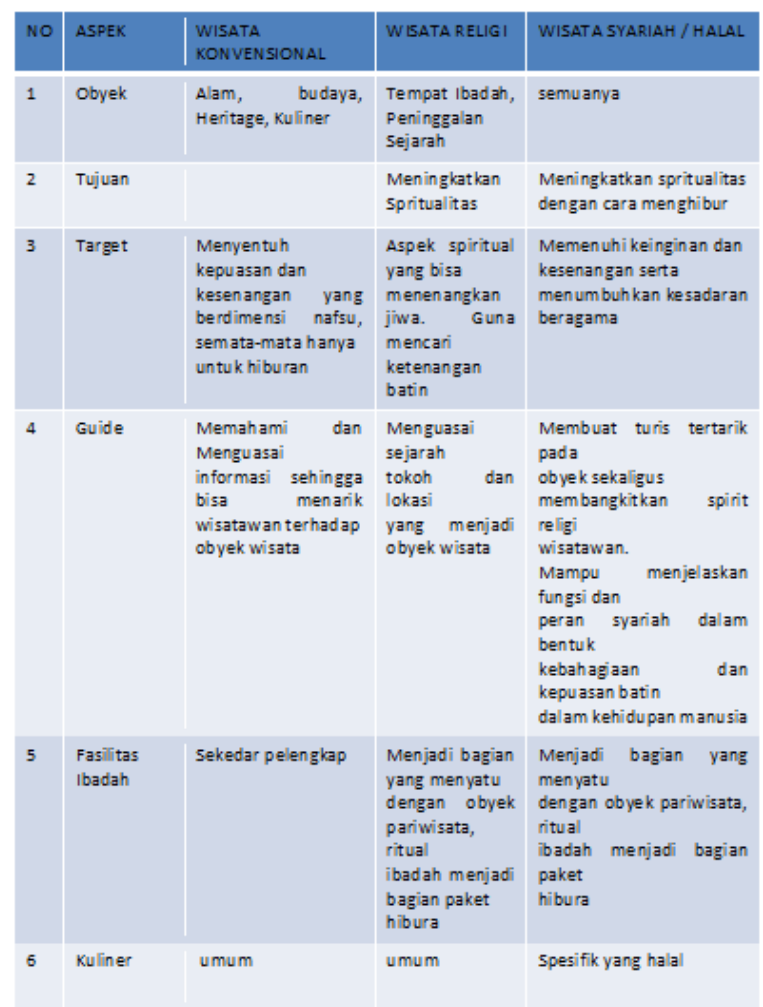

Sumber: MUI (2018)

Tabel 1

Perbedaaan antara Wisata Konvensional, Wisata Religi dan

Wisata Syariah 
kan insudtri besar karena industri pariwisata bukan industri yang dapat berdiri sendiri, tetapi suatu industri yang terdiri dari beberapa perusahaan yang menghasilkan produk atau jasa untuk para wisatawan. Fakta bahwa pariwisata berpengaruh terhadap publik adalah industri besar yang melibatkan pergerakan milyaran manusia ke seluruh dunia, maka dikatakan bahwa pergerakan tersebut adalah pengaruh langsung dan tidak langsung dari aktivitas diplomasi. Pada akhirnya, dampak yang diinginkan dari aktivitas diplomasi publik adalah pembentukkan gambaran positif mengenai suatu negara. Pariwisata Halal juga menjadi sarana untuk membangun citra Indonesia melalui Nation Branding. Nation Branding menjadi suatu hal yang penting di era globalisasi ini dikarenakan masing-masing negara ingin memperlihatkan citranya agar bisa bersaing secara kompetitif dalam menarik investasi, wisatawan, dan juga bantuan luar negeri.

\section{Aspek Ekonomi Dan Mata Pencarian}

Dalam perspektif ekonomi, keberadaan standar wisata halal dapat memberikan banyak benefit bagi kegiatan bisnis. Menurut Komunitas UMKM (20018) beberapa manfaat yang dapat diperoleh:

a. Peluang Produk Bisnis Memiliki Unique Selling Point (USP)

Dalam persaingan bisnis, competitive advantage merupakan hal utama yang harus dimiliki suatu produk. Dengan mengikuti sertifikasi wisata halal, produk akan memiliki nilai USP yang tinggi karena produk dinilai baik dimata masyarakat. Sehingga menarik trust masyarakat, dan menciptakan loyalitas

\begin{tabular}{|ll|}
\hline No & \multicolumn{1}{c|}{ Tahapan Kegiatan } \\
\hline 1 & Mengidentifikasi UKM dilingkungan Jatinangor \\
\hline 2 & Melakukan observasi dan jug a waw ancara kepada para pelaku bisnis (UKM) kuliner \\
\hline 3 & Menentukan bentuk sosialisasi yang paling tepat mengenai wis ata halal \\
\hline 4 & Melakukan kerjasama dengan MUI dan Dinas Pariwisata \\
\hline 5 & Menentukan jadw al penvuluhan \\
\hline 6 & Melaksanakan penyuluhan mengenai wis ata halal dan standar halal \\
\hline 7 & Melaksanakan FGD dengan para UKM \\
\hline
\end{tabular}

Tabel 2

Tahapan Kegiatan 
kuat dibenak konsumen produk.

b. Mengembangkan Pangsa Pasar Melalui Sertifikat Wisata Halal

Kekuatan trust masyarakat terhadap produk/makanan halal sangat tinggi, karena Indonesia merupakan negara yang penduduknya mayoritas muslim. Ke-halalan produk/ makanan sangat dijunjung tinggi oleh Islam, sehingga produk yang memiliki sertifikat halal akan mudah berkembang di Indonesia khususnya di Jatinangor. Bahkan, pengembangan pasar bisa dilakukan ke seluruh penjuru kota di Indonesia, hingga ke negara yang memiliki penduduk mayoritas muslim.

c. Memberikan Kepercayaan Tinggi bagi Konsumen.

Produk bersertifikat halal sudah pasti aman dikonsumsi, karena standar halal yang tinggi dan menjunjung tinggi kehigienisan baik secara proses maupun dalam makanan yang akan dihidangkan. Maka, dengan mudah produk bersertifikat Halal dapat dikonsumsi oleh konsumen. Hal tersebut akan meningkatkan permintaan produk, yang akhirnya meningkatkan profit usaha.

\section{Aspek Komunikasi}

Dalam suatu industri, pelaku industri perlu memberikan informasi mengenai industrinya. Misalkan, industri kuliner. Pelaku industri kuliner perlu menginformasikan dari menu makanannya, bahan-bahannya, serta halal atau tidaknya. Apalagi di Indonesia yang mayoritas masyarakatnya merupakan umat Islam. Meskipun tidak secara spesifik membuka usaha untuk umat muslim, tapi karena umat

\begin{tabular}{|c|c|c|c|}
\hline No & Indilk at or & $\begin{array}{c}\text { Base Line } \\
\text { (sebehm kegiatan) }\end{array}$ & $\begin{array}{c}\text { Penc apaian } \\
\text { Setelah Kegiat an }\end{array}$ \\
\hline 1 & $\begin{array}{l}\text { Menumbuhikan kesadaran } \\
\text { akan standarisasi halal } \\
\text { Memahami mengenai wisata } \\
\text { halal yang sehanusnya }\end{array}$ & $\begin{array}{l}\text { Mengetahui definisi halal } \\
\text { secara umum } \\
\text { Tidak tersosialisasikan } \\
\text { dengan baik }\end{array}$ & $\begin{array}{l}\text { Memahami dan lebih } \\
\text { menyadari pentingnya } \\
\text { sertifikasi halal } \\
\text { Jelas dan tersosialisaikan } \\
\text { dengan baik }\end{array}$ \\
\hline 3 & $\begin{array}{l}\text { Memahami prosedur yang } \\
\text { harus dipenuhi untuk } \\
\text { memenuhi standar halal }\end{array}$ & $\begin{array}{l}\text { Tidak mengetahui } \\
\text { prosedur yang seharuanya } \\
\text { untuk memenuhi standar } \\
\text { halal }\end{array}$ & $\begin{array}{l}\text { Mengetahui } r \text { dan } \\
\text { mamahami bagaimana } \\
\text { seharusnya standarisasi } \\
\text { halal }\end{array}$ \\
\hline
\end{tabular}

Tabel 3

Indikator Keberhasilan Kegiatan 
muslim menjadi mayoritas maka mempertimbangkan ke-halal-an usaha yang dimiliki adalah hal yang penting.

Selain dari industri makanan, industri yang berbasis jasa juga perlu mengkomunikasikan bahwa usahanya telah tersertifikasi halal agar konsumen tahu bahwa perusahaan tersebut memperhatikan aspek-aspek yang menjadi indikator wisata halal. Contohnya hotel yang menjamin kebersihan setiap kamar dan fasilitas lainnya, penyediaan sarung dan mukena, dan informasi arah kiblat. Selain itu menumbuhkan kesadaran dan pemahaman akan wisata halal tersebut kepada para pemangku pekentingan dan juga masyarakat (Pratiwi, Dida, Sjafirah, 2018).

\section{Aspek Budaya Masyarakat}

Jika sebuah restoran atau rumah makan mempunyai sertifikasi halal akan memberikan dampak baik pada usahanya. Dalam aspek budaya masyarakat jika sebuah rumah makan mempunyai sertifikasi halal maka pemilik usaha akan memahami apa saja yang boleh dilakukan dan tidak boleh dilakukan. Seperti contoh jika rumah makan menyediakan makanan berbahan dasar daging sapi, maka pemilik rumah makan akan mencari rumah potong hewan yang mempunyai sertifikasi halal juga, karena seperti yang diketahui budaya rumah potong hewan yang memotong sapi dilakukan dengan berbagai cara. Cara memotong sapi yang tidak sesuai dengan syariat Islam adalah menarik ekor sapi agar sapi dapat dijatuhkan dan dipotong, padahal dengan cara seperti itu akan membuat sapi stress dan mempengaruhi kualitas daging sapi. Selain itu dengan menebas ka- ki sapi, hingga sapi jatuh dan kesakitan kemudian baru dipotong. Budaya/kebiasaan seperti itu yang harus dihentikan, selain tidak sesuai dengan aqidah agama juga dapat mempengaruhi kualitas daging sapi. Jika budaya memotong hewan dalam masyarakat dapat diubah dengan cara sebelum memotong, rumah potong hewan menenangkan hewan tersebut dan tidak menununjukan pisau di depan hewan agar hewan tidak stress. Selain itu budaya juga merupakan faktor yang seharusnya mendukung wisata halal di Indonesia, karena mayoritas masyarakatnya beragama islam yang sudah seharuanya dalam segala kegiatan berdasarkan kapada nilai-nilai islam (Hamzana,2017).

\section{Sertifikasi Halal}

Berdasarkan pelaksanaan penyuluhan kepada para pelaku bisnis cefe, lestoran dan rumah makan di Jatinangor Bandung, maka terdapat beberapa informasi mengenai pentingnya sertifikasi halal di Indonesia yang disosialisasikan oleh MUI yaitu:

1. Indonesia memiliki populasi Muslim terbesar di dunia, sehingga terjaminnya kehalalan dari suatu produk yang dihasilkan menjadi syarat yang utama.

2. Indonesia menjadi salah satu destinasi perdagangan halal dan investasi bisnis halal tertinggi.

3. Pertumbuhan industri halal dunia sangat pesat. Jumlah dari produk halal yang ekspor di berbagai negara menjadi bukti bahwa halal merupakan isu global.

4. Memilki Produk Domestik Bruto (PDB) 
tertinggi sebagai anggota OKI

5. Indonesia memiliki budaya yang religius.

6. Halal merupakan isu yang sensitif, Beberapa contoh tentang isu halal :

- Kasus lemak babi (1988)

- Kasus MSG (media mengandung komponen dari babi) (2000)

7. Muslim Indonesia terdiri dari berbagai Mazhab

8. Fatwa merupakan produk kolektif (ijma 'jama'i) yang dikeluarkan melalui Komisi Fatwa, bukan oleh Mufti (individual).

\section{Prosedur Sertifikasi Halal}

Prosedur untuk mengajukan sertifikasi halal melalui beberapa proses dimulai dari proses pemenuhan persyaratan administrasi, kemudian apabila sudah terpenuhi akan dilaksanakan audit atau pengecekan dilapangan, atau pun pengecekan dilab tertentu sesuai dengan bisnis yang dijalankan, setelah itu maka akan dilakukan pengolahan hasil audit oleh MUI hingga pada akhirnya akan dikeluarkannya sertifikasi halal. Langkah-langkah yang harus dilakukan untuk memperoleh sertifikasi halal seperti gambar 1 .

\section{Prinsip Dasar Sertifikasi Halal}

Terdapat prinsip dasar untuk dapat terpenuhinya sertifikasi halal yang harus dipenuhi oleh semua perusahaan termasuk perusahaan yang bergerak dibidang kuliner yaitu:

- Kemampuan telusur : mengetahui dengan pasti dimana produk diproduksi, bagaimana proses produksinya, apa bahan yang digunakan, bagaimana prosedur produksinya dan bagaimana

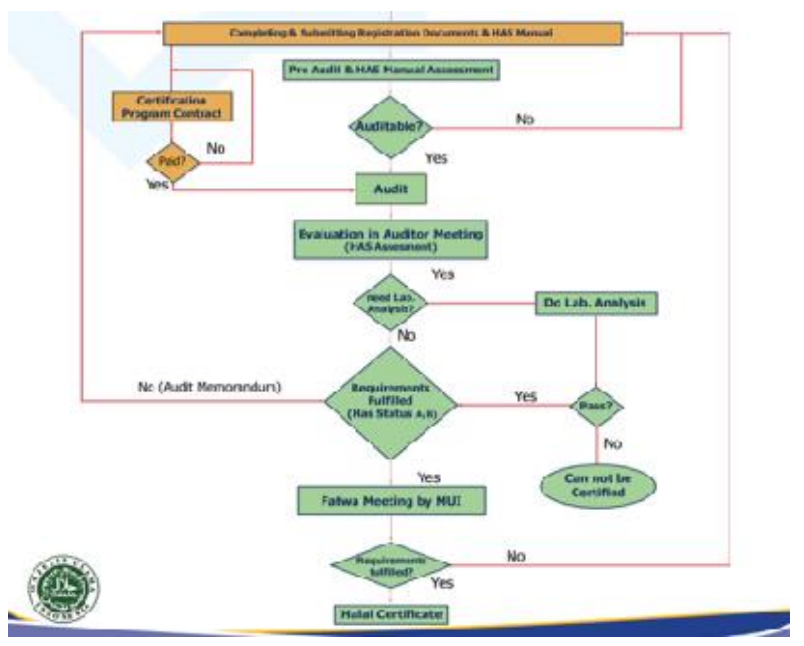

Sumber : MUI (2018)

Gambar 1

Prosedur Sertifikasi Halal 
status kehalalannya. Pengecekan dilakukan dengan cara audit untuk memeriksa bahan, formula, fasilitas, dokumen pendukung, dan sistem manajemen.

- Autentifikasi: memastikan tidak terjadi pemalsuan produk halal dengan produk haram, tidak terjadi percampuran bahan haram dalam produk halal dan tidak terjadi kontaminasi bahan haram ke dalam produk halal. Cara yang dapat dilakukan adalah dengan analisis laboratorium.

- Sistem jaminan halal: mendapatkan jaminan bahwa selama masa berlakunya sertifikat halal proses produksi halal akan dijaga kesinambungannya. Untuk menjamin hal tersebut maka dapat dilakukan dengan mempersyaratkan perusahaan untuk mengembangkan dan menerapkan
Sistem Jaminan Halal, kemudian penerapannya dinilai.

Berdasarkan gambar proses label halal pada gambar 2, dapat terlihat bahwa langkah pertama yang herus dimiliki oleh pelaku bisnis tersebut adalah memperoleh sertifikasi halal dari MUI dan selanjutnya memperoleh izin untuk mencantumkan logo halal dari BPOM RI.

Dengan dilaksanakan penyuluhan tersebut kepada para pelaku bisnis restoran, café dan rumah makan di Jatinangor bandung, maka informasi dan soasialisasi yang selama ini terhambat dan belum adanya media yang menjembatani antara MUI dan juga masyararakat, memberikan hasil dan informasi yang selama ini dibutuhkan oleh para pelaku bisnis kuliner tersebut.
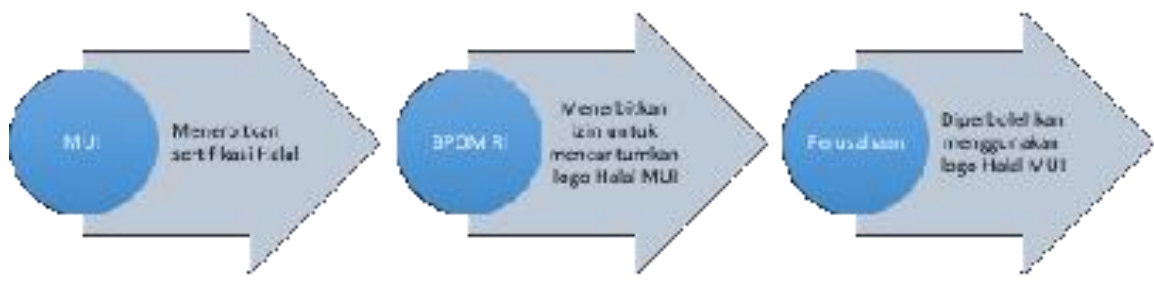

Sumber: MUI (2018)

Gambar 2

Proses Pelabelan Halal 
Bagian ini memuat hasil apa saja yang telah diperolah dalam pelaksanaan pengabdian kepada masyarakat dan kemudian dibahas dengan berbagai acuan yang ada.

\section{KESIMPULAN DAN SARAN}

\section{Kesimpulan}

- Komunikasi,sosialisasi dan informasi mengenai wisata halal dan pentingnya standarisasi halal dalam sektor kuliner masih diperlukan dan harus ditingkatkan. Adanya wadah yang dapat menjembatani antara MUI, dinas pariwisata, pemuda dan olah raga dengan para pelaku bisnis kuliner menjadi point yang sangat penting.

- Memperoleh sertifikasi halal memang bukan hal yang mudah akan tetapi bukan sesuatu yang tidak mungkin untuk diperoleh. Diperlukannya kesadaran akan pentingnya halal dalam menjalankan suatu bisnis mulai dari input, proses hingga outpt yang dihasilkan.

\section{Saran}

Perlu adanya pendampingan terhadap implementasi pariwisata halal khususnya terkait dengan sosialisasi sertifikasi halal bagi pelaku industri kuliner di Jatinangor. Minimnya sosialisasi dan informasi bagi masyarakat harus segera diatasi agar masyarakat dapat memaksimalkan potensi pariwisata halal. Beragam stakeholder baik pemerintah, MUI, dan pelaku industri kuliner atau asosiasinya harus bersinergis agar pariwisata halal ini dapat diimplementasikan dengan baik, karena terutama permasalahan regulasi atau payung hukum khususnya di daerah Kabupaten Sumedang yang belum terlembagakan. Diharapkan ke depan ada payung hukum daerah atau peraturan daerah yang dapat menjadi landasan implementasi Pariwisata Halal selain UndangUndang No 33 Tahun 2014 tentang Jaminan Produk Halal.

\section{DAFTAR PUSTAKA}

DISPARBUDPORA. (2017). Database Pariwisata Kabupaten Sumedang. Sumedang: DISPARBUDPORA.

Hamzana,A.A. (2017). Pelaksanaan Standarisasi Pelayanan Pariwisata Halal dalam Pengembangan Pariwisata di Nusa Tenggara Barat. Pena Justisia: Media Konumikasi dan Kajian Hukum, (Vol 17 No 2). Hlm. 1-16

Jaelani, A., Setyawan, E., \& Hasyim, N. (2016). Religious Heritage Tourism and Creative Economy in Cirebon: The Diversity of Religious, Cultures and Culinary. Journal of Social and Administrative Sciences (Vol 3 No1). Hlm 63-76.

Jaelani, A. (2017, 17 Januari). Halal tourism industry in Indonesia: Potential and Prospects. MPRA Paper No 76237. Diperoleh Agustus 2018, https:// mpra.ub.uni-muenchen.de/76237/

Komunitas UMKM. (2018, 31 Januari). Seberapa Besar Manfaat Mempunyai Sertifikasi Halal. Diperolah Agustus 2018, https://goukm.id/manfaatsertifikasi-halal/ 
Majelis Ulama Indonesia. (2018). Syarat Pendaftaran Sertifikasi Halal LPPOM MUI Provinsi Jawa Barat. Bandung: Majelis Ulama Indonesia.

Pratiwi, S.R., Dian, S., Sjafirah, N.A.(2018). Startegi Komunikasi dalam Membangun Awareness Wisata Halal di Kota Bandung. Jurnal Kajian Komunikasi (Vol 6 No 1). Hlm 78-90

Rahmadiansyah, A. (2018, 11 April). Indonesia Peringkat ke-Dua Destinasi Wisata Halal Dunia. Diperoleh Agustus 2018, https://www.cnnindonesia.com/gayahidup/20180411180123-269-290115/ indonesia-peringkat-ke-dua-destinasiwisata-halal-dunia pada 6 Mei 2018 Satriana , E.D., Faridah, H.,D. (2018). Wisata Halal : Perkembangan,Peluang dan Tantangan . Journal of Halal Product and Research (JHPR), Vol 1 No 2, MeiNovember 2018.

Suhendra. (2017). Benarkah RI Negara dengan Penduduk Muslim Terbesar Dunia?. Diakses di https://tirto.id/benarkah-rinegara-dengan-penduduk-muslimterbesar-dunia-cuGD pada 6 Mei 2018 Timothy, D.J., \& Olsen, H. (2006). Tourism, religion and spiritual journeys. Oxford: Routledge. 